УДК 364.4-053.2-056.24

\title{
ЭФФЕКТИВНОСТЬ СОЦИАЛЬНЫХ СЛУЖБ В ИНКЛЮЗИИ ДЕТЕЙ-ИНВАЛИДОВ
}

\author{
Корогодова Наталья Петровна ${ }^{1}$, \\ n.korogodova@yandex.ru; sociologsar@mail.ru \\ Зайцева Олеся Викторовна², \\ k_uip@ssla.ru \\ ${ }^{1}$ Саратовский государственный технический университет им. Ю.А. Гагарина, \\ Россия, 410054, г. Саратов, ул. Политехническая, 77 \\ ${ }^{2}$ Саратовскфя государственная юридическая академия, \\ Россия, 410056, г. Саратов, ул. Вольская, 1, корп. 5
}

Корогодова Наталья Петровна, социолог Научно-образовательного регионального центра мониторинговых исследований Саратовского государственного технического университета им. Ю.А. Гагарина.

Зайцева Олеся Викторовна, кандидат юридических наук, доцент кафедры уголовного и уголовно-исполнительного права Саратовской государственной юридической академии.

\begin{abstract}
Актуальность исследования определяется модернизацией основанной на политике инклюзии системы социального обслуживания и изменением форм помощи, оказываемой семьям, воспитывающим детей-инвалидов. Цель: исследование деятельности государственных социальных служб Саратовской области в контексте эффективности осуществляемых мероприятий, направленных на инклюзию детей с ограниченными возможностями здоровья, с инвалидностью. Методы: серии экспертных полуформализованных интервью со специалистами социальных служб Саратовского региона; анализ социологической литературы для составления критериев оценки эффективности деятельности социальных служб. Результаты. С позиций принципов инклюзии проанализирована доступность социальных служб и оказываемых ими социальных услуг, входящих в комплексные программы реабилитации. Определена инклюзивная направленность существующих социальнореабилитационных программ, основанных на поддержке, солидарности, социальной сплочённости, которые способствуют успешной социализации и инклюзии. Выявлены критические ограничения организационной культуры социальных служб, снижающих эффективность деятельности социальных сервисов в инклюзии социально уязвимых групп населения, в частности детей-инвалидов.
\end{abstract}

Ключевые слова: Инклюзия, эффективность социальных служб, дети-инвалиды.

Многочисленные исследования в области медицины и социологии способствовали изменению отношения общества к инвалидам, основанного ранее на незнании и непонимании всей сущности проблемы инвалидности. В современное время провозглашены принципы уважения человеческого достоинства, независимо от состояния здоровья, возраста, пола, вероисповедания и социального положения, соблюдения основных прав, в том числе право на медицинское обслуживание, образование, трудовую занятость, активное участие в жизни общества. Наблюдается смещение проблемы инвалидности к социальному аспекту, к понятиям интеграции, инклюзии, но нельзя исключать важность медицинского подхода. Ранее медицинская модель объяснения инвалидности была основана на диагнозе, патологии, на основе которых приписывался статус больного, ограниченного, требующего лечения, исправления, изоляции. В современном 
подходе к медицинской модели, совершенно иначе представлена проблема инвалидности - как необходимость оказания качественной медицинской помощи, большого спектра реабилитационных услуг, направленных на максимальное возможное восстановление.

Новые технологии позволяют на раннем этапе диагностировать заболевания и проводить необходимое лечение для восстановления или улучшения тех или иных функций организма человека. Таким образом, важно отметить необходимость применения обеих моделей при обращении к проблеме инклюзии людей с ограниченными возможностями здоровья. Обращение к статистическим данным показывает, что по состоянию на начало 2018 г. численность инвалидов составила в России около $8 \%$ населения страны. Почти столько же $(9 \%)$ от общего числа людей с ограниченными возможностями здоровья, получили инвалидность в детстве. Данная проблематика приобретает особую значимость, когда речь заходит о детях-инвалидах. Детей-инвалидов в нашей стране 655 000, что составляет 5,6 \% от общего числа. В Саратовской области 7145 детей в возрасте до 18 лет, имеющих инвалидность [1]. Статистика указывает на остроту проблемы и необходимость принятия эффективных мер, направленных на социальную инклюзию детей-инвалидов, которая возможно лишь при системном подходе, - медицинскую помощью, входящую в комплекс социальных услуг, слаженную работу нескольких ведомств и организаций, работу с социальным окружением детейинвалидов.

Дети-инвалиды и их семьи испытывают ряд трудностей, функциональных затруднений в результате заболевания, ограничения возможностей здоровья, вследствие неприспособленности физического пространства и социального окружения к их специальным потребностям, предрассудков общества в отношении инвалидности. Российские социальные службы формировались в пространстве выбора типа социальной поддержки и методов официального регулирования социальных проблем [2, с. 25]. Именно поэтому деятельность социальных служб в работе с детьми-инвалидами основана на социально-экологическом подходе и направлена на достижение инклюзии. В экосистему входят институты, оказывающие опосредованное влияние на семью в решении жизненных трудностей, в частности инклюзии детей инвалидов, СМИ, здравоохранение, образование, система социального обеспечения. Средства массовой информации способны не только влиять на формирование образа инвалидности и отношения общества к людям с ограниченными возможностями здоровья, с инвалидностью, транслировать ценности культуры, традиции, представления, но и выступать в роли информатора об учреждениях, оказывающих социальную помощь, защиту. Социальные службы выступают посредником, координатором между конкретным клиентом, потребителем услуг, его семьей и различными специалистами, учреждениями, обществом. От того, насколько качественно и эффективно осуществляется работа с детьми-инвалидами, зависит их будущее, благополучие, возможность вести самостоятельный образ жизни, обеспечивать себя, быть активным участником социальных отношений.

Деятельность социальных служб в отношении детей-инвалидов на сегодняшний день представляет собой комплекс социальных услуг: социально-педагогической, социально-психологической, социально-экономической помощи, правовой поддержки, организации социально-медицинской помощи, санаторно-курортного лечения, досуга, культурно-массовых развлечений. Для каждого ребенка разрабатываются программа реабилитации, система мероприятий, направленная на развитие возможностей ребенка инвалида и его семьи, некий стандартный алгоритм действий, утвержденный властью [3, с. 13]. Представленные направления деятельности социальных сервисов предпола- 
гают активное участие потребителей услуг для достижения инклюзии. Наличие инклюзивной культуры может стать показателем эффективности деятельности социальных служб. Оценивание инклюзии сегодня начинает рассматриваться как часть независимой оценки качества социального сервиса. На данный момент система оценивания, заключающаяся в определении критериев эффективности работы социальных служб и введении публичных рейтингов их деятельности, находится на стадии формирования. В. Ярская, Е. Ярская-Смирнова подчеркивают, что важной составляющей концепции качества социального обслуживания должен стать принцип инклюзии [4].

\section{Инклюзия в обществе детей-инвалидов: опыт социальных служб Саратовского региона}

Сегодня отмечается тренд рационализации и модернизации системы социальных сервисов, основанный на неолиберальных трансформациях государственной социальной политики, происходит разработка стандартов оценки эффективности деятельности социальных служб, отдельных специалистов, с целью управления организациями. В этом вопросе затрагивается тема профессионализации социальной работы, необходимости партнёрских взаимодействий между теоретиками и практиками, обмена информацией, знаниями, для рефлексии, выявления ошибок, разработки новых технологий посредством прикладных акционистских и партисипаторных исследований. В связи с этим возникает потребность в проведении мониторинга, результаты которого позволят «отслеживать процесс оказания услуг, их качество, степень достижения результатов, удовлетворенность получателей» [5, с. 112].

На протяжении последних лет научный интерес многих российских теоретиков и практиков обращен к проблеме оценки эффективности деятельности социальных служб. Большой вклад в социальные исследования социальных сервисов внесли отечественные ученые, которые разработали критерии эффективности учреждений социальной сферы, методики определения эффективности их деятельности (И.Ю. Давыдова, Д.В. Зайцев, Л.И. Кононова, А.Н. Попова, П.В. Романов, И.С. Ромнычев, И.С. Трапезникова, И.Е. Шандаков, Е.Р. Ярская-Смирнова). Заслужили признание многие профильные учебные пособия Е.И. Комаровой, П.Д. Павленка, Е.И. Холостовой, О.Г. Прохоровой, в которых представлены теоретико-методологические аспекты исследования эффективности социальных услуг.

Проблематика эффективности деятельности социальных служб в инклюзии детейинвалидов не является принципиально новой в социологических исследованиях, однако приобретает актуальность в условиях каждой из проводимых реформ. Изменения в социальной политики, влекут принятие законодательных мер, определяющих специфику деятельности учреждений социальной сферы, ориентацию на те или иные принципы работы, определяют категории потенциальных клиентов, способы и формы оказания социальной поддержки, помощи, защиты. Концепция модернизации системы социальной защиты предусматривает повышение доступности качества оказываемых услуг. Перемещение зарубежного опыта в российскую действительность требует разработки собственных (национальных) критериев и показателей эффективности работы социальных служб, адаптированных к российским реалиям [6].

Важной выступает экономическая составляющая [7], лежащая в основе всех социальных проектов и программ, формирующая эффективную финансовую основу деятельности учреждений социальной защиты. Сложность оценки деятельности социальных служб заключается в отсутствии возможности количественного измерения, т. к. важно качество оказываемых услуг для достижения поставленной цели. 
Деятельность социальных сервисов необходимо совершенствовать, с учетом социокультурных изменений. Для этого необходимо осуществлять оценку социальной деятельности, получаемых социальных эффектов [8]. Подходы к оценке эффективности деятельности социальных служб могут осуществляться различными способами, иметь разные формы [9]. Системный анализ подразумевает определение важных переменных в начале программы и по её завершении - статистический анализ этих связей. Анализ достигнутых целей на протяжении длительного времени считался самым распространённым, результаты деятельности оценивались посредством стандартизированных тестов для измерения успехов клиентов, которые могут быть оценены только в определенном контексте. Трансакционная модель фокусирована на восприятии происходящих событий, детальном анализе данных, полученных неформализованным способом при личном взаимодействии с участниками программы. Обратная связь позволяет разработать качественные стандарты, выступающие в качестве модели социального обслуживания $[10$, с. 6]. Иллюминативная модель подразумевает описание и интерпретацию, изучение влияния программы на определённые социальные ситуации, их недостатки и достоинства, влияние на опыт и жизнь участников. Еще одна модель оценки эффективности, свободная от цели, направлена на поиск эффектов [11] и мультиэффектов.

Несмотря на существующие модели, зачастую оценка эффективности процесса социального обслуживания [5] ориентирована лишь на число клиентов и оказанных услуг, т. к. оценку результата работы и качества реализации услуг выполнить гораздо сложнее и затратнее как с темпоральной, так и с финансовой точки зрения. Понятие «качество» социальной услуги включает в себя результат, результативность и эффективность. Национальные стандарты социального обслуживания призваны обеспечивать качество их предоставления. Для этого необходима единая система оценки социального обслуживания, контроль на всех этапах предоставления социокультурных, психологопедагогических услуг, управление качеством оказываемых услуг. Оценка эффективности деятельности социальных служб в социально-образовательной инклюзии детейинвалидов предполагает системный анализ: учет количественных и качественных показателей социального учреждений, социальной программы, обращение к современных научно-методологическим разработкам.

Социальные службы играют ключевую роль в инклюзии детей с инвалидностью и представлены комплексом организаций разного профиля, выполняющих единую миссию: комплексные центры социального обслуживания населения, социальнореабилитационные центры для несовершеннолетних, реабилитационные центры для детей и подростков с ограниченными возможностями, центры социальной помощи семье и детям и иные. В идеале деятельность социальных сервисов направлена на восстановление статуса, реабилитацию детей-инвалидов, их инклюзию в общество. Однако на практике инклюзивная составляющая существует номинально, лишь как ориентир, дискредитируя миссию социальных организаций - содействие в реализации прав клиентов, улучшение качества их жизни. Зачастую представители социальных учреждений не понимают сути инклюзии, специфики социального сопровождения данного процесса, оценки его эффективности, что свидетельствует о нарушении конституционных прав детей с инвалидностью.

В 2019 г. при финансовой поддержке РФФИ в рамках научного проекта № 19-011-00542 проведено исследование инклюзии детей-инвалидов на примере социальных служб Саратовской области посредством анализа доступности социальных сервисов (в том числе информационной). Для этого применялись: полуформализованное интервью с руководителями и специалистами по социальной работе $(N=20)$, включенное наблюдение, 
анализ документов. В целях анализа эффективности оказываемых услуг исследована деятельность пяти государственных бюджетных учреждений г. Саратова и Саратовской области, оказывающих социальную помощь семьям, воспитывающим детей-инвалидов.

Социальные службы являются важным звеном, аккумулирующим ресурсы помощи в инклюзии детей-инвалидов. Инклюзия сама по себе - социальная ценность, однако данное понятие становится отражением уровня впитывания, включения инклюзии через социальные практики и технологии, т. е. социально-технологические процессы $[9,12]$. Н. Луман отмечал, что передача многих общественных функций, в том числе и функций социальной помощи, организованным социальным системам является тенденцией [13], несмотря на то, что данные системы недостаточно развиты [14]. Недостаточная сформированность, незрелость инклюзивной культуры социальных служб, отсутствие понимания ее значимости становятся основной проблемой, препятствующей эффективному и оперативному оказанию помощи потенциальным клиентам [4]. Именно инклюзивная культура способна вывести социальные службы на новый уровень, предусматривающий отказ от исключения отдельных групп граждан, т. к. социальная сплоченность напоминает обществу о важности коллективного внимания к любым проявлениям дискриминации, неравенства, маргинальности или эксклюзии [15], выступает механизмом социальной сплоченности и солидарности.

До настоящего времени актуален вопрос профессионализации социальной помощи. Респонденты отмечают ужесточение требований к образованию специалистов:

- «если еще несколько лет назад специалистом по сочиильной работе мог быть любой человек, любой профессии и специальности, то сейчас требуется выстее профильное образование» (замдиректора социальной службы, г. Саратов).

Внутри организаций социального обслуживания населения существуют определенные формы оценки эффективности. Контроль работы специалиста осуществляется заведующим отделением, также директором учреждения путем устной отчетности на совещаниях, проверки журналов оказанных услуг, личных дел и программы реабилитации семей, состоящих на учете в социальной службе.

Еще одной новой формой поддержки специалистов является так называемое наставничество:

- «...когда специалисты работают в паре, выступая друг для друга помощником в разработке программы, оказания услуги, последующей рефлексии» (специалист по социальной работе, г. Саратов).

Эффективность деятельности учреждения социального обслуживания представляет сложный многоплановый процесс ввиду того, что стандартные критерии эффективности в данной системе могут быть не показательны [16]. Как отмечают сами информанты, оценка эффективности в большей степени осуществляется количественным методом:

- «Министерству удобнее принимать отчеты в том виде» (спеииалист по социальной работе, г. Саратов).

Такие показатели, как достижение определенного результата или эффекта в работе с ребенком-инвалидом, могут быть отражены в патронажном отчете или в случае поступления запроса вышестоящими инстанциями. При этом подобные отчеты характеризуются формальностью и обобщенностью. Для специалистов по социальной работе, социальных педагогов, непосредственно осуществляющих работу с ребенком, оценка эффективности своей деятельности с точки зрения качества представляет наибольшую значимость, нежели количество проведенных занятий. Важно отметить значимость количественного показателя при оценке деятельности специалиста, отделения и службы в целом. Количество важно не только в отчетных формах, но также при начислении стимулированных выплат, кото- 
рые напрямую зависят от количества оказанных услуг, семей, состоящих на учете. В некоторых случаях происходит «приписка» услуг, предоставление информации может быть представлено как социально-педагогическая или социально-правовая услуга тем самым действительность искажается. Либо практикуется необоснованная дифференциация услуги на микроуслуги. Например, одна услуга информирования клиента может дробиться на три услуги: предоставление информационного буклета (1), информационного листка (2), вербальное разъяснение процедуры получения услуги (3) и т. д.

Исследование эффективности социального обслуживания, направленного на инклюзию клиентов, затрагивает тему доступности услуг и социальных сервисов. Доступность социальных услуг для потенциальных клиентов изучалось в аспекте информационной и средовой доступности. Информированность потенциальных клиентов, семей, воспитывающих детей-инвалидов, о возможности получения бесплатной социальной, юридической, психологической, педагогической помощи является первым шагом на пути к инклюзии. Обеспечение информированности клиента об услуге, порядке и условиях ее получения является одним из критериев эффективности деятельности социальных служб, отраженных в Национальном стандарте РФ ГОСТ Р 52496-2005 «Социальное обслуживание населения. Контроль качества социальных услуг. Основные положения» (утв. приказом Федерального агентства по техническому регулированию и метрологии от 30 декабря 2005 г. № 533-ст) [17]. Обращение клиента за помощью в социальные учреждения является первым шагом, этапом в работе с ребенком-инвалидом, возможностью получить доступ к основным сферам общественной жизни.

В 2011 г. в России начала реализовываться государственная программа «Доступная среда», цель которой сводится к созданию условий, обеспечивающих равный доступ инвалидов, наравне с другими гражданами, к физическому пространству: транспорту, информации, связи, объектам и услугам [18]. Инклюзивный дизайн становится гарантией доступности архитектурной среды, транспортных средств любым категориям горожан [19]. Изучение средовой доступности свидетельствует о наличие барьеров в доступе к социальным службам [20]. Несмотря на транспортную доступность, учреждение находится вдали от остановок общественного транспорта, дорога имеет неровное покрытие, спуски и подъемы, не оснащена тротуарными зонами, на пути отсутствуют указатели месторасположения социального учреждения, что указывает на труднодоступность. В последние годы здания социальных служб стали оснащаться специальными указателями, покрытиями пола, покрытиями первых и последних ступеней на лестнице. Прием граждан осуществляется в кабинете, расположенном первым от входа. Вход в здание во многих случаях остается затруднительным, несоответствующим требованиям строительных ГОСТов и стандартов. Выявленные барьеры указывает на несовершенство инклюзивной городской среды, инклюзии социальных служб.

Анализ сайтов социальных учреждений, которые оказывают помощь семьям, воспитывающим детей-инвалидов, свидетельствует о предоставлении неполной информации или содержит информацию формального характера, которая не вызывает доверия у граждан. Потенциальные потребители услуг на основе предоставленной информации, считают, что данные услуги не способны решить трудности их семей. Многие нуждающиеся в социальной поддержке семьи вовсе не знают об учреждениях социальной помощи семье и детям, расположенных на территории Саратовской области и г. Саратова. Зачастую люди, впервые столкнувшиеся с трудной жизненной ситуацией, остаются наедине со своей проблемой, не способны её самостоятельно разрешить и не владеют информацией о социальных учреждениях, деятельность которых направлена на инклюзию, адаптацию, интеграцию людей, оказавшихся в плену обстоятельств. Спе- 
циалисты по социальной работе считают, что многие семьи могут не осознавать проблемности и сложности возникшей в семье критической ситуации:

- «это одна из проблем дезадаптации, когда семья изначально не видит, что что-то не так, когда семье кажется, что на самом деле проблем нет или никто не может помочь» (замдиректора соичильной службы, г. Саратов).

Другие испытывают страх обращения в социальные службы:

- «даже проще, когда есть барьеры, связанные со страхом. Этот барьер, в рамках первичного воздействия специиалисту, удается снизить» (замдиректора социальной службы, г. Саратов).

Низкий уровень организации информационной компании государственных социальных учреждений влияет на осведомленность людей, нуждающихся в помощи. Люди узнают о возможности получения социальной помощи - бесплатной юридической консультации по вопросам оформления льгот, субсидий, компенсаций, социальнопсихологической, социально-педагогической помощи всем членам семьи, обучающих мероприятий по принципу «сарафанного радио» - от людей, имеющих такую же проблему и опыт обращения в социальные службы. В ходе экспертного интервью с заместителем директора одной из социальных служб Саратовской области нам удалось узнать о способах информирования населения о социальных услугах, предоставляемых бесплатно гражданам, не имеющих достаточных личных и семейных ресурсов для решения возникших трудностей. В социальных службах практикуется, как одно из направлений деятельности:

- «информирование беременных женщин о возможности получать сочииальную помощь и поддержку в целях предотвращения и сокращения абортов; информация размещена на стендах в женских консультащиях»,

- «осуществляются выходы специиалистов, юристов и педагогов-психологов в школь для работы с подростками для профилактики безнадзорности и беспризорности несовершеннолетних» (замдиректора социальной службы, г. Саратов).

Сегодня отсутствует такая практика, как раздача листовок на улице, баннеры, нет информационных плакатов на остановках общественного транспорта, в торговоразвлекательных центрах, детских садах, образовательных учреждениях, благотворительных организациях, что является минусом информационной кампании социальных служб. Ведь не только беременные женщины и подростки могут нуждаться в помощи и поддержке специалистов социальных служб. Острую необходимость в профессиональной помощи испытывают семьи, воспитывающие особых детей, т. е. детей, имеющих ограничения по здоровью: дети с ДЦП, с синдромом Дауна, дети, страдающие аутизмом; много еще различных проблем, которые отличают этих детей от своих сверстников. Таким семьям нужна не только финансовая поддержка, как принято считать, но также профессиональная помощь и поддержка узких специалистов (педагоговпсихологов, дефектологов, логопедов).

Посещение, а тем более участие в культурно-массовых мероприятиях имеют пролонгированное значение, оказывают мощное влияние на развитие ребенка, его способность ориентироваться в обществе и в определенной степени интегрироваться в него, адаптироваться к условиям внешней среды, окружению. Интерес и значительный общественный резонанс представляют обучающие программы и творческие мастерские для детей, которые преподают люди с инвалидностью. По мнению специалистов, такая форма организации обучения является не только: 
- «возможностью личностного развития детей, но также своего рода «надеждой на будущее своих особых детей» для родителей» (специилист по сочииальной рабоmе, г. Саратов).

Примером такого обучения является «программа по обучению компьютерной грамоте», созданная на базе одного из центров помощи семье и детям. Руководство центра подчеркивает особую роль именно такой формы организации работы с семьей, воспитывающей ребенка с ограниченными возможностями, когда социальный педагог, специалист по социальной работе выступают примером успешной социализации, самореализации и инклюзии. В ближайшем будущем планируется развитие волонтерского направления в работе с семьями с детьми-инвалидами, в котором будут принимать участие волонтеры-инвалиды.

\section{Заключение}

Обращение к вопросу эффективности социального обслуживания обусловлено продвижением идей рационализации социальной помощи, социальной политики по оптимизации реестра льготников с учетом реальных потребностей, интересов и приоритетов реципиентов. Ориентация деятельности социальных служб на инклюзию, разработка инклюзивных программ работы с клиентами продиктованы направленностью социальной политики на создание инклюзивного общества. Происходит распространение инклюзивных практик в работе с клиентами, при этом организационная культура социальных организаций требует обращения к теоретическим источникам, имеющимся прикладным исследованиям в области социальной работы с целью обогащения знаниями, изучения опыта эффективного социального обслуживания. Представленные направления деятельности социальных служб свидетельствуют о стремлении к формированию организационной культуры социальных сервисов на основе принципов инклюзии, некоторые инклюзивные практики уже функционируют и являются востребованными, возникают новые, следующие тенденциям развития инклюзивного общества.

Полученные в ходе исследования результаты о специфике социальноинклюзивной работы с детьми-инвалидами свидетельствуют о её развитии в контексте современной системы социального обслуживания, социальной защиты граждан и определенной эффективности данной деятельности. Основные проблемные точки данной системы связаны с излишней бюрократизацией, мизерностью оплаты труда специалистов социальных служб, наряду с высокой социальной ответственностью, сложностью повседневной деятельности, приводящей к раннему профессиональному выгоранию работников. Инклюзивная основа социальной работы содействует формированию инклюзивной организационной культуры социальных служб, повышению эффективности их деятельности, качества организационно-административных процессов и практик, что позитивно сказывается на экономичности, действенности и результативности предоставляемых услуг. Применение в комплексе различных видов оценки социальной деятельности, учет качественных и количественных показателей работы социальных организаций, конкретных социальных программ и практик, рейтинга специалистов социальных служб, обратной связи способствуют получению объективных данных об эффективности деятельности социальных служб и оптимизируют процессы социального прогнозирования и планирования.

Исследование выполнено при финансовой поддержке РФФИ в рамках научного проекта № 19-011-00542. 


\section{СПИСОК ЛИТЕРАТУРЫ}

1. Статистика по детям инвалидам в РФ. URL: https://sakuramed.ru/obshie-stati/statistika-po-detyaminvalidam-v-rf (дата обращения 17.10.2019).

2. Наберушкина Э.К. Об инициативах и переменах в системе содействия занятости // Социальные работники как проводники перемен / под ред. Е.Р. Ярской-Смирновой, Н.В. Сорокиной. - М.: Вариант: ЦСПГИ, 2012. - С. 23-41.

3. Романов П.В., Ярская-Смирнова Е.Р., Сорокина Н.В. Агенты и структуры социальной работы // Социальные работники как проводники перемен / под ред. Е.Р. Ярской-Смирновой, Н.В. Сорокиной. М.: Вариант: ЦСПГИ, 2012. - С. 7-23.

4. Ярская-Смирнова В.Н., Ярская-Смирнова Е.Р. Инклюзивная культура социальных сервисов // Социологические исследования. - 2015. - № 12. - С. 133-140.

5. Романов П.В., Ярская-Смирнова Е.Р. Модернизация социального обслуживания: ориентация на результат // SPERO. - 2011. - № 14. - С. 107-120.

6. Романычев И.С. Механизмы и критерии оценки эффективности деятельности учреждений социального обслуживания // Приволжский научный вестник. - 2012. - № 3. - С. 64-71.

7. Давыдова И.А. Система показателей оценки эффективности деятельности учреждений социального обслуживания // Научные труды центра перспективных экономических исследований. - 2011. № 4. - C. 188-193.

8. Максимова М.Н. Теоретико-методологические и технологические основы формирования и использования ресурсов социального обслуживания: монография - М.: Социальное обслуживание, 2018. $256 \mathrm{c.}$

9. Топчий Л.В. Система управления социальным обслуживанием населения // Социальное обслуживание. - 2005. - № 1. - С. 5-16.

10. Романычев И.С., Стрельникова Н.Н., Топчий Л.В. Социальная квалиметрия, оценка качества и стандартизация социальных услуг. - М.: Дашков и К, 2018. - 184 с.

11. Оценка эффективности деятельности учреждений социальной поддержки населения / под ред. П.В. Романова, Е.Р. Ярской-Смирновой. - М.: Московский общественный научный фонд: ЦСПГИ, 2007. $-234 \mathrm{c}$.

12. Ярская В., Бабаян И. Инклюзивная молодежная политика нового поколения // Вестник СГТУ. 2014. - № 4. - С. 149-157.

13. Луман Н. Социальные системы. Очерк общей теории. - М.: Наука, 2007. - 641 с.

14. Луман Н. Формы помощи в процессе изменения общественных условий // Социологический журнал. - 2000. - № 1/2. - С. 16-35.

15. Алешина М. Социальная сплоченность: концептуализация понятия // Вестник Саратовского государственного технического университета. - 2012. - № 1. - С. 216-222.

16. Трапезникова И.С. Методика выявления эффективности деятельности муниципального учреждения социального обслуживания и критерии ее оценки // Фундаментальные исследования. - 2015. № 11. - С. 824-827.

17. ГОСТ Р 52496-2005 Социальное обслуживание населения. Контроль качества социальных услуг. Основные положения. URL: http://docs.cntd.ru/document/1200043281 (дата обращения 15.10.2019).

18. Сафронов К.Э. Подходы к формированию, управлению и оценке доступной среды // Экономические науки. - 2012. - № 2. - С. 157-163.

19. Наберушкина Э.К. Право на город в фокусе инклюзии // Социальное развитие города: дизайн инноваций: Материалы Международной научно-практической конференции «Социальное развитие города: дизайн инноваций». - Саратов: СГТУ им. Ю.А. Гагарина, 2013. - С. 8-14.

20. Шестопалова Ю. Безбарьерная среда для маломобильных граждан как объект социального проектирования // Науковедение. - 2011. - № 6. URL: http://naukovedenie.ru/sbornik6/20.pdf (дата обращения 10.10.2019).

Поступила 21.01.2020 2. 
UDC 364.4-053.2-056.24

\title{
EFFECTIVENESS OF SOCIAL SERVICES IN INCLUDING CHILDREN WITH DISABILITIES
}

\author{
Nataliya P. Korogodova1, \\ n.korogodova@yandex.ru; sociologsar@mail.ru \\ Olesya V. Zaitseva², \\ k_uip@ssla.ru \\ 1Yuri Gagarin State Technical University of Saratov, \\ 77, Politechnicheskaya street, Saratov, 410054, Russia \\ 2Saratov State Law Academy, \\ 1, bld. 5, Volskaya street, Saratov, 410056, Russia
}

Nataliya P. Korogodova, sociologist, Yuri Gagarin State Technical University of Saratov.

Olesya V. Zaitseva, Cand. Sc., associate professor, Saratov State Law Academy.

The relevance of the research is determined by modernization of the social service system, changes in the forms of assistance provided to families raising children with disabilities, based on the policy of inclusion. The aim of the research is to study the activities of the state social services of the Saratov region in the context of the effectiveness of ongoing measures aimed at the inclusion of children with disabilities. Methods: a series of expert semi-formal interviews with specialists of social services in the Saratov region; analysis of sociological literature to compile criteria for evaluating the effectiveness of social services. Results. From the standpoint of inclusion principles, the authors have analyzed the accessibility of social services and the social services they provide included in comprehensive rehabilitation programs. The inclusive orientation of existing social rehabilitation programs based on support, solidarity, social cohesion, contributing to successful socialization and inclusion, was revealed. The authors identified the critical limitations of organizational culture of social services, reducing the effectiveness of social services in inclusion of socially vulnerable groups of the population, in particular children with disabilities.

Key words: Inclusion, efficiency of social services, children with disabilities.

The research was financially supported by the RFBR within the scientific project no. 19-011-00542.

\section{REFERENCES}

1. Statistika po detyam invalidam v RF [Statistics on children with disabilities in the Russian Federation]. Available at: https://sakuramed.ru/obshie-stati/statistika-po-detyam-invalidam-v-rf (accessed 17 October 2019).

2. Naberushkina E.K. Ob initsiativakh i peremenakh $\mathrm{v}$ sisteme sodeystviya zanyatosti [On initiatives and changes in the employment promotion system]. Sotsialnye rabotniki kak provodniki peremen [Social workers as agents of change]. Eds. E.R. Yarskaya-Smirnova, N.V. Sorokina. Moscow, Variant LLC, TSSPGI Publ., 2012. pp. 23-41.

3. Romanov P.V., Yarskaya-Smirnova E.R., Sorokina N.V. Agenty i struktury sotsialnoy raboty [Agents and structures of social work]. Sotsialnye rabotniki kak provodniki peremen [Social workers as agents of change]. Eds. E.R. Yarskaya-Smirnova, N.V. Sorokina. Moscow, Variant LLC, TSSPGI Publ., 2012. pp. 7-23. 
4. Yarskaya-Smirnova V.N., Yarskaya-Smirnova E.R. Inclusive culture of social services. Sotsiologicheskie issledovaniya [Sociological Studies], 2015, no. 12, pp. 133-140. In Rus.

5. Romanov P.V., Yarskaya-Smirnova E.R. Modernizatsiya sotsialnogo obsluzhivaniya: orientatsiya na rezultat [Modernization of social services: a focus on results]. SPERO. 2011, no. 14, pp. 107-120.

6. Romanychev I.S. Mekhanizmy i kriterii otsenki effektivnosti deyatelnosti uchrezhdeniy sotsialnogo obsluzhivaniya [Mechanisms and criteria of an estimation of efficiency of activity of establishments of social service]. Privolzhskiy nauchny vestnik [Volga Scientific Bulletin], 2012, no. 3, pp. 64-71. In Rus.

7. Davydova I.A. Sistema pokazateley otsenki effektivnosti deyatelnosti uchrezhdeniy sotsialnogo obsluzhivaniya [The system of indicators for assessing the effectiveness of social service institutions]. Nauchnye trudy tsentra perspektivnykh ekonomicheskikh issledovaniy, 2011, no. 4, pp. 188-193.

8. Maksimova M.N. Teoretiko-metodologicheskie $i$ tekhnologicheskie osnovy formirovaniya i ispolzovaniya resursov sotsialnogo obsluzhivaniya [Theoretical and methodological and technological foundations of the formation and use of social services]. Moscow, Sotsialnoe obsluzhivanie Publ., 2018. 256 p.

9. Topchiy L.V. Sistema upravleniya sotsialnym obsluzhivaniem naseleniya [The social service management system of the population]. Sotsialnoe obsluzhivaniye, 2005, no. 1, pp. 5-16.

10. Romanychev I.S., Strelnikova N.N., Topchiy L.V. Sotsialnaya kvalimetriya, otsenka kachestva $i$ standartizatsiya sotsialnykh uslug [Social qualimetry, quality assessment and standardization of social services]. Moscow, Dashkov i K Publ., 2018. 184 p.

11. Otsenka effektivnosti deyatelnosti uchrezhdeniy sotsialnoy podderzhki naseleniya [Evaluation of the effectiveness of the activities of social support institutions]. Eds. P.V. Romanova, E.R. Yarskaya-Smirnova. Moscow, Moscow Public Science Foundation, TSSPGI Publ., 2007. 234 p.

12. Yarskaya V., Babayan I. Inklyuzivnaya molodezhnaya politika novogo pokoleniya [Inclusive youth policy of the new generation]. Vestnik SGTU, 2014, no. 4, pp. 149-157.

13. Luman N. Sotsialnye sistemy. Ocherk obshchey teorii [Social systems. Essay on the general theory]. Moscow, Nauka Publ., 2007. 641 p.

14. Luman N. Formy pomoshchi $\mathrm{v}$ protsesse izmeneniya obshchestvennykh usloviy [Forms of assistance in the process of changing social conditions]. Sotsiologicheskiy zhurnal, 2000, no. 1/2, pp. 16-35.

15. Aleshina M. Sotsialnaya splochennost: kontseptualizatsiya ponyatiya [Social cohesion: conceptualization of the concept]. Vestnik Saratovskogo gosudarstvennogo tekhnicheskogo universiteta, 2012, no. 1, pp. 216-222.

16. Trapeznikova I.S. Metodika vyyavleniya effektivnosti deyatelnosti munitsipalnogo uchrezhdeniya sotsialnogo obsluzhivaniya i kriterii ee otsenki [The methodology for identifying the effectiveness of the municipal institution of social services and the criteria for its evaluation]. Fundamentalnye issledovaniya, 2015, no. 11, pp. 824-827.

17. GOST R 52496-2005. Sotsialnoe obsluzhivanie naseleniya. Kontrol kachestva sotsialnykh uslug. Osnovnye polozheniya [SS R 52496-2005 Social services for the population. Quality control of social services. The main provisions]. Available at: http://docs.cntd.ru/document/1200043281 (accessed 15 October 2019).

18. Safronov K.E. Podkhody k formirovaniyu, upravleniyu i otsenke dostupnoy sredy [Approaches to the formation, management and assessment of the accessible environment]. Ekonomicheskie nauki, 2012, no. 2, pp. 157-163.

19. Naberushkina E.K. Pravo na gorod v fokuse inklyuzii [The right to the city in the focus of inclusion]. Materialy Mezhdunarodnoy nauchno-prakticheskoy konferentsii. Sotsialnoe razvitiye goroda: dizayn innovatsiy [Social development of the city: design of innovations. Materials of the International scientificpractical conference]. Saratov, SSTU named after Yu.A. Gagarin, 2013. pp. 8-14.

20. Shestopalova Yu. Bezbaryernaya sreda dlya malomobilnykh grazhdan kak obyekt sotsialnogo proektirovaniya [Barrier-free environment for people with limited mobility as an object of social design]. Naukovedeniye, 2011, no. 6. Available at: http://naukovedenie.ru/sbornik6/20.pdf / (accessed 10 October 2019).

Received: 21 January 2020. 